\title{
The Optimization Model Construction of Multimodal Transportation Route for Dangerous Goods
}

\author{
Chun-Xin ZHAI ${ }^{1, a,{ }^{*}}$, Cui MENG ${ }^{1, b}$, Hai-Ping SUI ${ }^{1, c}$, Ke-Xin $\mathrm{LI}^{1, \mathrm{~d}}$ \\ ${ }^{1}$ School of Shandong Jiaotong University, Ji'nan250357, China. \\ acxzhai840678775@126.com, 'b1759809105@qq.com, '865426949@qq.com, \\ d1443788960@qq.com \\ ${ }^{*}$ Chun-Xin ZHAI
}

Keywords: Dangerous goods, Multimodal transport route optimization, Multi objectives optimization algorithm.

\begin{abstract}
Problems of multimodal transport for dangerous goods were analyzed in this paper. By establishing the multimodal transport system, and in order to minimize the total cost of transportation, the risk in transshipment, the linear programming model and multi-objective optimization algorithm were designed. The multimodal transport route for dangerous goods were discussed in detail in the paper.
\end{abstract}

\section{Introduction}

Through the establishment of route optimization model by combining the factors of cost, time, risk and so on, we considered that the transportation of dangerous goods should balance cost and time, reduce the process risk, maximize the transportation efficiency. It has great practical significance to accelerate the rapid development of China's dangerous goods industry and improve the service level of logistics and transportation industry.

\section{Description of Multimodal Transport for Dangerous Goods}

Assuming a dangerous goods is through the multimodal transport network which has various nodes in the public, there are also different types of goods other than dangerous goods to be shipped for different batches with different starting points and end points. The conditions of transportation cost, time and risk of all kinds of goods on each section of each mode of transportation are known, and so are the cost, time and risk of transshipment at each node. It is necessary to transport any dangerous goods from its starting point to the destination, to take into account the arrival time of the goods and road capacity constraints, so as to determine the various batches of dangerous goods, choose transport route and the route of the road transport.

\section{Construction of Multimodal Transportation Route Optimization Model for Dangerous Goods}

\section{Model Assumptions}

In the multimodal transport network of dangerous goods. There are many routes of transportation, and they have their individual advantages. There are many kinds of starting and ending points of dangerous goods, and so are the types of dangerous goods. In order to make modeling analysis easier, we made the following assumptions.

(1)Assuming that all constants are known and are determined;

(2)Assuming that at least one type of transport is used in each section;

(3)Assuming that each shipment of dangerous goods only chooses one transport route;

(4)Assuming that each road segment in the path has capacity constraints;

(5)Assuming that each shipment of dangerous goods has a service time requirement;

(6)In order to make the symbols easier to be distinguished, it is assumed that there is only one type of dangerous goods. 


\section{Symbolic Description}

We made dangerous goods multimodal transport network for $\boldsymbol{G}=\{\boldsymbol{V}, \boldsymbol{A}, \boldsymbol{A}\}, \boldsymbol{V}$ represents the collection of individual nodes, $\boldsymbol{A}$ and $\boldsymbol{A}$ is a set of undirected arcs, They represent all the sections and all sections of the road transport. Hypothesis $\boldsymbol{l}$ indicates the index of dangerous goods, Its starting point is $\boldsymbol{o}^{\boldsymbol{k}}$, Its end is $\boldsymbol{d}^{\mathbf{k}}$, Its flow is $\boldsymbol{v}^{\mathbf{l}}$. Service time requirement is $\boldsymbol{s}^{\boldsymbol{k}}$, A total of $\boldsymbol{m}$ batches of dangerous goods. The collection of all dangerous goods as $\boldsymbol{r}_{\boldsymbol{i}}^{\boldsymbol{*}}$, mean $\boldsymbol{l}=\mathbf{1 , 2}, \boldsymbol{m}, \boldsymbol{l} \in \boldsymbol{L}$. Let $\mathbf{k}$ be the index of the mode of transport. Noting the collection of all modes of transport to $\boldsymbol{K}$, mean $\boldsymbol{k} \in \boldsymbol{K}, \boldsymbol{c}_{\overline{\boldsymbol{i}}}^{\mathbf{z}}$, $\boldsymbol{r}_{\boldsymbol{z}}^{\mathbf{z}}$ and $\boldsymbol{t}_{\overline{\boldsymbol{j}}}^{\mathbf{k}}$ respectively represents the cost, time and risk of transporting dangerous goods on the road $(i, j)$, using the first $\mathrm{k}$ mode of transport, They respectively represent unit costs, unit risk, and total time at I for the transfer of dangerous goods from $\mathrm{P}$ to form $\mathrm{Q}$. In consideration of the risk fairness constraint. If there is too much risk caused by the frequent use of the road in some sections of the road. Limiting the maximum capacity of each section to $\boldsymbol{b}_{\overline{\boldsymbol{i}}}$.

\section{Establish the Model}

From what has been discussed above, we can build the model as shown below:

$$
\begin{aligned}
& \min Z_{1}=\sum_{l \in L} \sum_{(i, j) \in A} \sum_{k \in E} v^{l} c_{i \bar{y}}^{k} x_{i j}^{l k}+\sum_{l \in L} \sum_{i \in V} \sum_{p \in K} \sum_{q \in K} v^{l} \alpha_{i}^{p q} y_{i}^{\phi p d}
\end{aligned}
$$

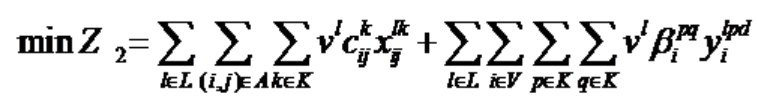

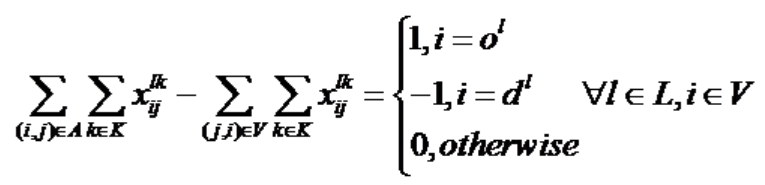

$$
\begin{aligned}
& \sum_{k \in \mathbb{K}} x_{i j}^{l k} \leq 1 \quad \forall l \in L,(i, j) \in A \\
& \sum_{(j, i) \in A} x_{\bar{j}}^{l p}+\sum_{(i, j) \in A} x_{i \bar{j}}^{l q}-1 \leq y_{i}^{l p q} \\
& \forall l \in L, i \in V, p \in K, q \in K \\
& \sum_{p \in K} \sum_{q \in \mathcal{K}} y_{i}^{h p q} \leq \mathbf{1} \forall l \in L, i \in K \\
& \sum_{(i, j) \in A} \sum_{k \in \mathbb{K}} t_{i j}^{k} x_{i j}^{k k}+\sum_{i \in V} \sum_{p \in \mathbb{K}} \sum_{q \in X} \gamma_{i}^{p q} y_{i}^{p q} \leq s^{t} \\
& \forall l \in L \\
& \sum_{l \in L} \sum_{k \in \mathbb{K}} v^{l} x_{i j}^{l_{k}} \leq b_{i j} \forall(i, j) \in A \\
& x_{i j}^{l k} \in(0,1) \quad \forall l \in L,(i, j) \in V, k \in K \\
& y_{i}^{l p q} \in(0,1) \quad \forall l \in L, i \in V, p \in K, q \in K
\end{aligned}
$$

In the above model, (1)and(2) of the objective function respectively: (1) to minimize the total cost, including the total transportation costs and total transport costs, (2) to minimize the total risk. (3) - (10) of constraint condition respectively. (3) for each batch of dangerous goods in each node of the flow conservation constraint, type (4) for each batch of dangerous goods on the various sections by up to a choice of the mode of transportation, (3), (4) and (9) to guarantee each batch of dangerous goods can only be the only one from its starting point to its end point path, and cannot be divided. (5) and (6) for each batch of dangerous goods transportation continuity constraint, including: (5) to ensure that the decision variables of $\boldsymbol{x}_{\boldsymbol{\gamma}}^{\boldsymbol{k}}$ and $\boldsymbol{y}_{\hat{\boldsymbol{z}}}^{\boldsymbol{T}}$ relations correctly, specific 
interpretation, If the first $\boldsymbol{l}$ batches of dangerous goods are used respectively $\boldsymbol{p}$ and $\boldsymbol{q}$ arrive

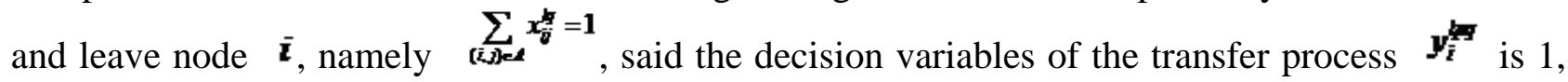
otherwise 0 ; (6) for each batch dangerous goods in each section of the limitation of only one mode of transport. (7) the sum of the total transport time and the total transit time of each batch of dangerous goods shall not exceed the time of delivery; (8) the quantity of dangerous goods needed to meet the limit of the capacity of each section of the road, so that the risk degree of each region is controlled in a certain range; (9) and (10) for the nonnegative integer constraints.

\section{Example Analysis of Multimodal Transportation Route Optimization of Dangerous Goods}

A company has a dangerous goods multimodal transport network. As shown in Fig.1. Two batches of flammable liquid cargo to be shipped on L1 and L2. Start and end points are 1 to 5 and 1 to 7. Their transportation volume is 30 tons. They use a $20 \mathrm{ft}$ tank container shipment, delivery time is $12 \mathrm{~h}$ and 20h.Each arc has a weight of four tuples, in which the first three weights represent the unit cost, the unit risk and the total time. The unit parameter is used as a container; the fourth weight indicates the capacity limit of the section, the unit is t. In practical application, the capacity limit of each section is mainly set by the government, which is related to the risk bearing capacity of the road section and the risk fairness.
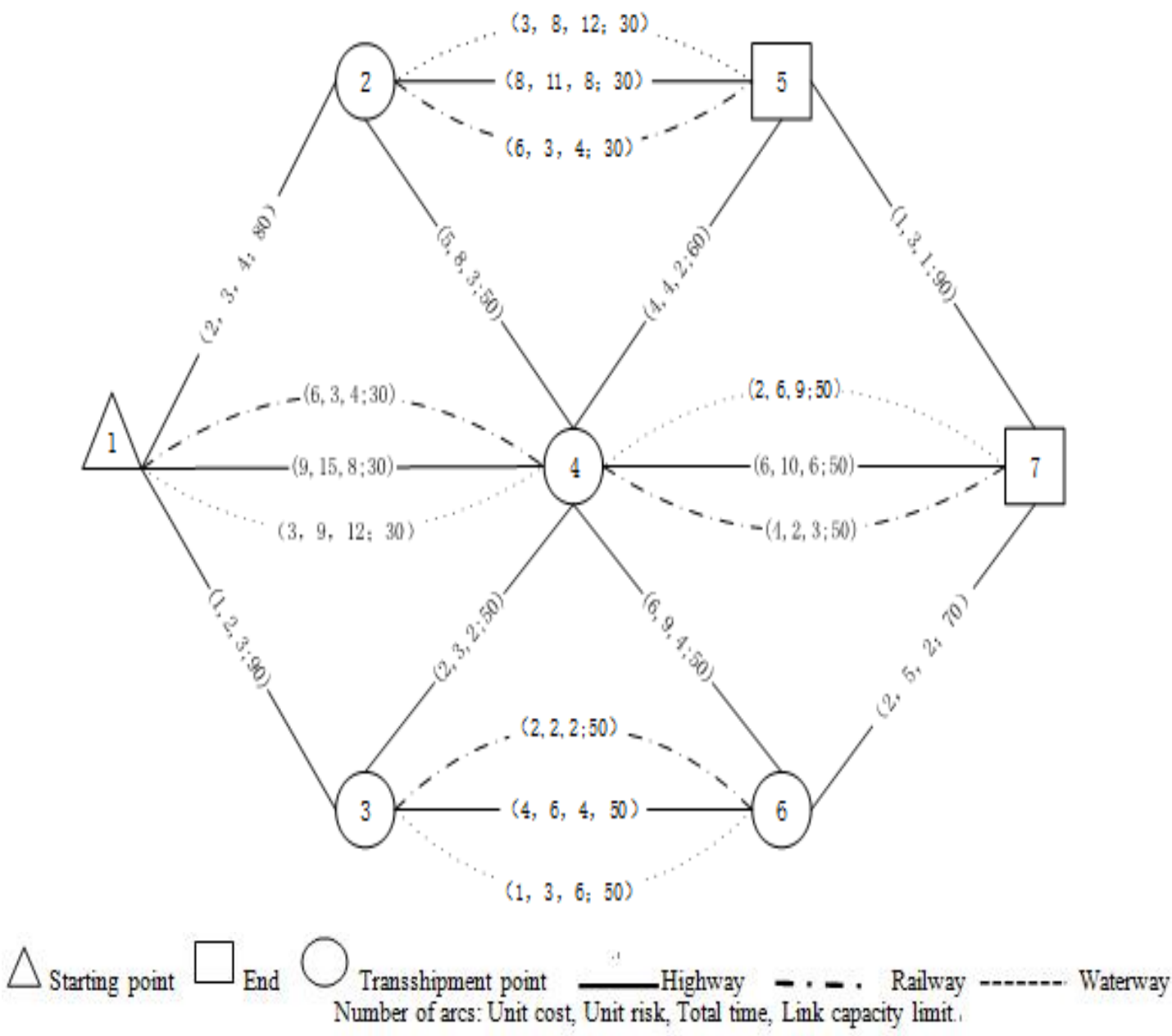

Fig.1 Example analysis

For the above example, The full route based multi-objective optimization algorithm is designed by using MATLAB 8. A total of seven non inferior solutions are obtained, as shown in Table 1. 
Table 1 Multi-objective Optimization Results

\begin{tabular}{|c|c|c|c|}
\hline Solution & Path information & total cost & Tota \\
\hline \multirow{2}{*}{$\begin{array}{l}\text { Non inferior } \\
\text { solution } 1\end{array}$} & $l_{1}: 1$ - highwav -2- railwav -5 & \multirow{2}{*}{19} & \multirow{2}{*}{12} \\
\hline & $l_{2}: 1$ - railway -4- railway -7 & & \\
\hline \multirow{2}{*}{$\begin{array}{l}\text { Non inferior } \\
\text { solution } 2\end{array}$} & $l_{1}: 1$ - highwav -2 - railwav -5 & \multirow{2}{*}{15} & \multirow{2}{*}{19} \\
\hline & $l_{2}: 1$ - highway -3- highway -4- waterway -7 & & \\
\hline \multirow{2}{*}{$\begin{array}{l}\text { Non inferior } \\
\text { solution } 3\end{array}$} & $l_{1}: 1$ - highwav -2-railwav -5 & \multirow{2}{*}{16} & \multirow{2}{*}{18} \\
\hline & $l_{2}: 1$ - highway -3- railway -6- highway - & & \\
\hline \multirow{2}{*}{$\begin{array}{l}\text { Non inferior } \\
\text { solution } 4\end{array}$} & $l_{1}: 1$ - highway -2- railway -5 & \multirow{2}{*}{15} & \multirow{2}{*}{19} \\
\hline & $l_{2}:$ 1- highway -3- waterway -6- highway -7 & & \\
\hline \multirow{2}{*}{$\begin{array}{l}\text { Non inferior } \\
\text { solution } 5\end{array}$} & $l_{1}: 1$ - highway -3- highway -4- highway -5 & \multirow{2}{*}{17} & \multirow{2}{*}{14} \\
\hline & $l_{2}: 1$ - railway $-4-$ railway -7 & & \\
\hline \multirow{2}{*}{$\begin{array}{l}\text { Non inferior } \\
\text { solution } 6\end{array}$} & $l_{1}: 1$ - highway -3- highway -4- highway -5 & \multirow{2}{*}{14} & \multirow{2}{*}{20} \\
\hline & $l_{2}:$ 1- highway -3- railway -6- highway -7 & & \\
\hline \multirow{2}{*}{$\begin{array}{l}\text { Non inferior } \\
\text { solution } 7\end{array}$} & $l_{1}: 1$ - highway -3- highway -4- highway -5 & \multirow{2}{*}{13} & \multirow{2}{*}{21} \\
\hline & $l_{2}: 1$ - highway -3- waterway -6- highway -7 & & \\
\hline
\end{tabular}

Multimodal transport has many advantages. In the test case, only the highway can complete the transportation task, so only the comparison of road transport and multimodal transport. Using the same computing platform and tools, the multi-objective optimization algorithm is used to obtain the noninferior route of highway transportation, and only one optimal solution is obtained. As shown in Table 2. Compared with the results in Table 1 and Table 2, the noninferior solution 6,7 of multimodal transport is superior to the optimal solution for the total cost and the total risk. Although the total cost of the optimal solution for road transport is slightly lower than that of the multimodal non dominated solution 1,2,3,4,5, this will increase the risk value of the whole process. Therefore, on the whole, compared to the transport, multimodal transport of dangerous goods is a more economical and environmentally friendly mode of transport.

Table 2 Transport Optimization Results

\begin{tabular}{|l|l|l|l|l|}
\hline $\begin{array}{l}\text { Type of } \\
\text { shipping }\end{array}$ & $\begin{array}{l}\text { Solution } \\
\text { number }\end{array}$ & Path information & $\begin{array}{l}\text { total } \\
\text { cost }\end{array}$ & $\begin{array}{l}\text { Total } \\
\text { risk }\end{array}$ \\
\hline Highway & $\begin{array}{l}\text { optimum } \\
\text { solution }\end{array}$ & $\mathbf{K}: 1$ - highway -3- highway -4- highway -5 & 14 & 22 \\
\cline { 2 - 5 } & $\mathbf{2}: 1$ - highway -3- highway -6 highway -7 & 2 & \\
\hline
\end{tabular}

\section{Summary}

The multimodal transport for dangerous goods is becoming the new industry in the logistics circle, more and more logistics companies are paying much attention on it. In order to realize the route optimization of multimodal transport for dangerous goods, the double objectives linear programming model has been established in this paper, then the multi-objective optimization algorithm that based on Barrett analysis and its characteristics was designed, then the multimodal transport combination way for dangerous goods finally was found through calculating and 
analyzing to the models, hope the suggestions can bring up the better development of multimodal transport for dangerous goods.

\section{References}

[1]Li ZHOU, Jun-Tao LI, Bing-Wu LIN. Dangerous goods logistics standard system construction in our country. Standard science, 2010.9.(11)

[2]Li-Gang CUI. Multimodal transport of goods transportation mode choice studies (master).

Chongqing: transportation university in Chongqing, 2009:17-18.

[3]Jian LU. Based on the transport rationalization of multimodal transport path optimization research. Youth years, 2015.(6)

[4]Xia-Yan SHEN. Risk analysis of road transport of dangerous goods and the route optimization research (Dr). Xian: Chang-an university, 2009. 